\title{
Effectiveness of Online Consumer Product Review: The Role of Experiential Information
}

\author{
Jaebong Son \\ College of Business \\ California State University, Chico \\ json@csuchico.edu
}

\author{
Dan J. Kim \\ G. Brint Ryan College of Business \\ University of North Texas \\ dan.kim@unt.edu
}

\author{
Chang E. Koh \\ G. Brint Ryan College of Business \\ University of North Texas \\ chang.koh@unt.edu
}

\begin{abstract}
Product reviews as consumer-generated information have drawn great attention from researchers and practitioners. A substantial academic effort has been made to comprehend factors influencing the helpfulness of reviews, largely centering on a few quantitative factors (e.g., star rating, review length). However, research investigating qualitative aspects of product reviews still lags, though product reviews consist mainly of peer consumers' experiences and opinions. In this study, we use the smartphone reviews to investigate consumers' experiences and opinions in relation to review helpfulness. By statistical analysis, we demonstrate that consumers' experiential information plays a significant role to make product reviews helpful. We furnish additional evidence of the statistical results by predictive analytics. Our findings suggest that consumers' experiential information conveys meaningful implication to better understand the nature of product reviews. Therefore, this study contributes to the extant literature of e-commerce and to practitioners to utilize the consumer reviews of their products.
\end{abstract}

\section{Introduction}

Online shopping or e-commerce has significantly affected our shopping experience. Thanks to the advancement of the Internet technology and mobile devices, customers can explore and purchase products online from the comfort of home or on the go. One impediment for online customers is the inability to physically evaluate the quality of a product [1]. This inability increases uncertainty about product quality [2], leading to seeking product-related information [3]. Marketer-generated content (MGC; e.g., product description) and user-generated content (UGC; e.g., personal experiences and opinions) are two predominant information sources for online buyers, in the sense that MGC provides marketer- or producer-oriented product information, while UGC centers on consumer-oriented product information [4]. Research has shown that UGC's information significantly reduces the uncertainty of product quality [e.g., 5, 6] and, furthermore, its positive effect on consumers' purchase decisions is larger than that of MGC [e.g., 4].

Despite the prominent value of UGC, most of previous UGC studies estimated UGC's information value by investigating a few quantitative factors-e.g., reviews' star rating for sentiment, reviews' length by the number of words for the amount of information - rather than examining qualitative attributes-e.g., review content [e.g., 7, 8]. However, since information is encoded in a message by a set of agreed signs and symbols, a message's information can be unearthed by decoding its signs and symbols (or understanding its content) [9]. The importance of considering a qualitative information is well demonstrated in Pavlou and Dimoka's eBay study [10]. They performed content analysis on sellers' feedback text comments to extract seller's reputation information (e.g., benevolent, credibility), which cannot be captured by other quantitative features (e.g., the number of transactions, sellers' rating). In addition, using the qualitative attributes extracted from text comments, they were able to explain $50 \%$ of the variance in price premiums $\left(\mathrm{R}^{2}=50 \%\right)$, a greater explanation power compared to 20 $30 \%$ of the variance reported in the existing literature $\left(\mathrm{R}^{2}=20 \%-30 \%\right)$.

The aim of our study is to investigate the value of consumer-oriented product information in UGC. To achieve this goal, we utilize consumers' product reviews of smartphones for the following three reasons. First, consumer product reviews (hereafter 'product reviews' or 'reviews') are the most popular form of UGC that includes diverse topics, ranging from product quality to consumer satisfaction and experiences [11]. Second, the extent to which each product review is informative can be gauged by its number of helpful votes, called review helpfulness [7]. Last, as a mixture of state-of-the-art technologies, a smartphone is evaluated by its functional 
factors (e.g., CPU, camera), aesthetic appearances (e.g., design, material), and/or its users' usage experiences (e.g., ease of use, sound quality) [12]. The rest of the paper proceeds as follows. We review the extant literature on online product reviews and then develop hypotheses. Following that, we describe our methodology, data, and the results of our hypothesis testing. We conclude with discussions of our findings and the limitations for future research.

\section{Literature reviews}

Product reviews as "peer-generated product evaluation" play a substantial role in consumer purchase decisions and product sales [7, 13, 14]. Research carried out by TripAdvisor in 2015 reported the following two interesting findings. First, in 2014, $73 \%$ of its users posted reviews to share their staying experiences with other travelers. Second, more than $50 \%$ of its global users showed unwillingness to book a hotel without any reviews. ${ }^{1}$ In a similar vein, a study that surveyed 104 online shoppers in Germany reported that around $85 \%$ of the participants read product reviews 'often' or 'very often' before making purchase decisions [15]. With the awareness of the importance of fellow consumers' reviews, the majority of companies provide a product review section for their prospective customers [16]. Certainly, consumer-oriented information conveyed in product reviews becomes valuable for prospective customers.

Nonetheless, not all product reviews are equally informative. An increasing body of literature on product reviews has attempted to comprehend factors explicating the extent of reviews' informativeness [e.g., 17]. One such factor is the review content. Mudambi and Schuff [7] found that review depth (or review extensiveness) measured by each review's number of words is positively associated with review helpfulness (e.g., the more informative, the more helpful votes [13]). They assumed that a longer review conveys a larger quantity of information and thus includes more product details and specific usages. A similar relationship between the number of words and the amount of information was repeatedly evaluated under different operationalizations, such as review elaborateness [18] and review length [19]. On the other hand, Son, et al. [6] discovered that review breadth quantified by the number of topics (or themes) per review positively affected review helpfulness. ${ }^{2}$ Their proposition was that as a review expresses more topics, it is supposed to diagnose more diverse aspects of products. Review sentiment is another popular determinant to estimate review informativeness. By calculating the proportion of

\footnotetext{
${ }^{1}$ https://www.tripadvisor.com/TripAdvisorInsights/w828
}

positive and negative words per review, Baek, et al. [20] concluded that reviews with a considerably higher proportion of negative words than positive ones were perceived more helpful. Similarly, Cao, et al. [21] analyzing reviews to count the number of words in pros and cons, respectively, showed that the longer cons reviews include, the more helpful votes they receive.

In fact, the majority of previous studies on product reviews gauged the value of consumer-oriented information by conveniently relying on the number of words (e.g., review depth; the length of pros and cons) or a group of associated words (e.g., review breadth). However, the information value of a product review stating "this phone's battery lasts longer" could not be fully represented by the review length of 5. Research exploring what specific personal experiences consumers share online and how the value of such personal information is perceived still lags. As an exploratory study, our research evaluates qualitative aspects of online product reviews by focusing on consumers' experiences and opinions.

\section{Hypothesis development}

Seeking product information is a crucial behavior of customers to mitigate uncertainty about product quality $[1,2]$. Product quality is assessed by objective and perceived quality [22]. Objective quality involves products' measurable and verifiable features (i.e., search attributes), whereas perceived quality entails consumers' subjective responses to products (i.e., experience attributes) [23]. The distinction between objective and perceived quality seems especially important for technology products, as technology (i.e., objective attributes) changes consumers' usage patterns (i.e., experience attributes) [e.g., 24]. Therefore, it is highly probable that customers whose intention is to purchase a technology product try to assess (1) its objective quality by examining its technological features and (2) its perceived quality by obtaining peer consumers' individualized values.

In this line of reasoning, smartphones are an interesting technology product, because both quality factors significantly influence customers' product quality [e.g., 25, 26]—smartphones' technological features as search attributes contribute to lessening uncertainty about objective quality, while consumers' personal values on smartphones as experience attributes contribute to mitigating uncertainty about perceived quality. To put it differently, by separating experience attributes affecting perceived quality from search attributes affecting objective quality, we can better estimate the value of consumers' personal experiences

\footnotetext{
${ }^{2}$ A topic is determined by a set of frequently co-occurred words.
} 
and opinions. Hence, we use product reviews of smartphones available on the Best Buy website. Based on tags and terms that Best Buy has already processed, are also considered as an experience attribute that requires consumers' subjective responses [e.g., 30]. The example excerpts are (1) “... been having problems with

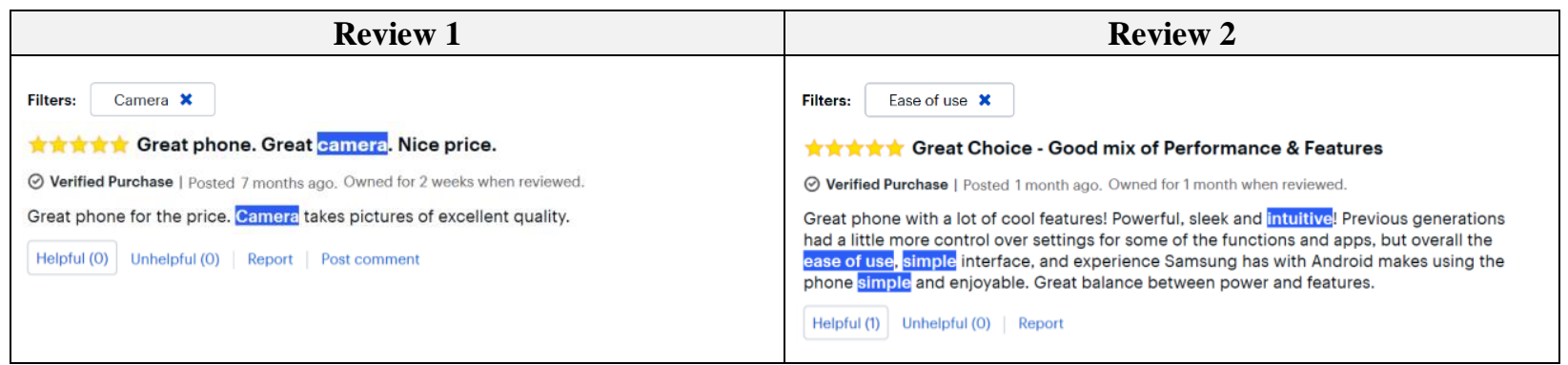

Figure 1. Example product reviews with tags and terms (e.g., camera; easy to use)

we were able to identify smartphone-related features mentioned in product reviews. For example, Review 1 in Figure 1 is tagged with "Camera," because it includes a term "camera," while Review 2 is tagged with "Easy to use" due to "intuitive," "ease of use," and "simple" in its content. After collecting these tags and terms, we grouped tags by interpreting the meaning of each tag's terms. As a result, we formed 9 tag groups, each of which is categorized into either experience or search attribute (see Table 1).

By applying the characteristics of search attributes (e.g., objective, measurable), we considered Processor, Memory, Screen, and Camera to convey fact-centric information. Examples are "Apple A10 chip" for Processor, "32GB of storage; 6gb ram" for Memory, "5inch screen" for Screen, and "12-megapixel" for Camera. Such factual information can be also found in MGC, and MGC may provide more details (e.g., [27]). As the primary purpose of this study is to investigate the value of experiential information conveyed in product reviews, we do not establish hypotheses on these search attributes. $^{3}$

On the other hand, Ease-of-Use, Design, Performance, Sound, and Battery Life may not be objectively measurable attributes, but peer consumers' experiences derived from their actual usage and preferences. Thus, we deemed these attributes as experience-centric attributes. For instance, consumers' ease-of-use is a personal experience that can be gained only after using a smartphone. In fact, a technology product's ease-of-use aspect is known to positively influence customers' intention to use [e.g., 28]. Similar to an ease-of-use attribute, smartphones' esthetics (i.e., design) seem to be far different from objectively measurable information [e.g., 29] - e.g., "... the all glass body will not hold up well against concrete ...," "... the all glass design gives it a luxury feel to it ..." Similarly, smartphone features associated with sound my sound cutting out during calls ..." and (2) “... I just wish the speaker volume was a little louder ..." Unlike search attributes, experience attributes reflect consumers' personal evaluation. Therefore, we formulate the following three hypotheses.

Hypothesis 1 (H1). Reviews including consumers' ease-of-use experience receive more helpful votes than those without usage experiences.

Hypothesis 2 (H2). Reviews conveying consumers' smartphone esthetics (e.g., design) receive more helpful votes than those without aesthetic appearance.

Hypothesis 3 (H3). Reviews including consumers' sound experience are perceived more helpful than those without it.

How well a technology product functions affects its perceived quality [22]. A smartphone's performance is determined not by relying on individual componentse.g., processor, memory, screen-but by integrating such components together [12]. Therefore, consumers' performance experience resulting from actual usage patterns would better reflect a smartphone's overall performance. A few performance-related excerpts are "... there is no lag with anything so far 8 hours into the device ...", “... in 2 weeks of moderate usage I have experienced no performance issues ...," and "... a bit sluggish in performance if you compare it with Samsung s7/s7 edge ..." In a similar vein, a smartphone's battery life is not determined solely by its battery capacity, but affected by several factors, such as processing power, sensors, consumers' charging habits, etc. [31]. Viewed in this light, consumers' battery usage experience may be a better information source than that described in MGC. The following excerpts show diverse consumer experiences regarding battery: (1) “... wifi calling

${ }^{3}$ Search attributes are included as control variables in the empirical models. 
Table 1. Tags and terms

\begin{tabular}{|c|c|c|c|}
\hline \multicolumn{2}{|r|}{ Groups } & Tags & Frequent terms appeared in smartphone reviews ${ }^{\dagger}$ \\
\hline \multirow{13}{*}{ 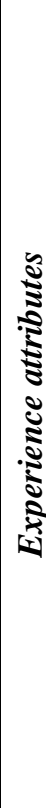 } & Easy-Use & easy to use & $\begin{array}{l}\text { easy (2352), easy to use (1307), friendly (309), easier (261), user friendly (243), } \\
\text { simple (145), ease of use (121), intuitive (92) }\end{array}$ \\
\hline & \multirow{5}{*}{ Design } & design & beautiful (342), design (338), look (320), looking (285), looks (267), sleek (222) \\
\hline & & comfortable & hand (316), hands (189), pocket (129), fits (121), my hand (95) \\
\hline & & color & color (471), black (191), gold (161), colors (115), rose gold (102) \\
\hline & & $\begin{array}{c}\text { build } \\
\text { quality }\end{array}$ & durable (88), sturdy (31), durability (30), fragile (25), crack (25) \\
\hline & & material & glass (223), metal (35), plastic (26), aluminum (20), materials (10) \\
\hline & \multirow{4}{*}{ Sound } & $\begin{array}{l}\text { sound } \\
\text { quality }\end{array}$ & sound (330), volume (93), sound quality (81), audio (66), loud (50) \\
\hline & & speaker & $\begin{array}{l}\text { speaker (286), speakers (141), front facing speakers (10), external speaker (8), facing } \\
\text { speaker (6) }\end{array}$ \\
\hline & & $\begin{array}{c}\text { headphone; } \\
\text { music }\end{array}$ & $\begin{array}{l}\text { jack (202), headphone (170), headphone jack (144), headphones (122), headphone } \\
\text { port (5); music (185), music player (8) }\end{array}$ \\
\hline & & bluetooth & bluetooth (123), blue tooth (10), bluetooth connection (2) \\
\hline & \multirow{2}{*}{ Performance } & speed & fast (1530), faster (370), speed (333), performance (223), lag (84) \\
\hline & & reliability & reliable (107), freezing (10), defective (7), unreliable (1) \\
\hline & Battery-Life & battery & $\begin{array}{l}\text { battery (2863), battery life (1614), charge (443), charging (398), charger (199), } \\
\text { wireless charging (101) }\end{array}$ \\
\hline \multirow{6}{*}{ 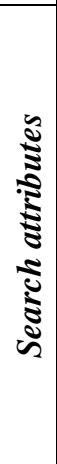 } & Processor & processor & processor (225), process (49) \\
\hline & Memory & $\begin{array}{l}\text { ram; } \\
\text { memory }\end{array}$ & $\begin{array}{l}\text { ram (40); memory (431), expandable memory (59), extra memory (10), memory } \\
\text { space (6) }\end{array}$ \\
\hline & \multirow{2}{*}{ Screen } & screen & $\begin{array}{l}\text { screen (2768), pixel (729), display (502), bright (158), screen size (142), large screen } \\
\text { (76), screen resolution (62), curved screen (57) }\end{array}$ \\
\hline & & touchscreen & $\begin{array}{l}\text { touch screen (40), touchscreen (6), screen sensitivity (5), touch sensitivity (3), touch } \\
\text { response (1) }\end{array}$ \\
\hline & \multirow{2}{*}{ Camera } & camera & $\begin{array}{l}\text { camera (4608), camera quality (101), lens (61), new camera (58), camera features } \\
(45), \text { focus (37) }\end{array}$ \\
\hline & & $\begin{array}{l}\text { picture } \\
\text { quality }\end{array}$ & pictures (1087), photos (518), picture (331), pics (210), resolution (201) \\
\hline
\end{tabular}

$\dagger$ term (frequency) - e.g., easy to use (1307): 'easy to use' appeared 1307 times in our review data; only up to top 10 terms are shown.

feature also reduces the battery consumption when there is low signal ...," (2) “... after a full 24 hours of use I still end the day with over $40 \%$ battery life regardless of what I am doing on it ...," (3) “... battery life last me most of my day from 6 a.m. when I take it off the charger to about 9:30 at night before it even hits a $15 \%$ mark ...," and (4) “... performance/battery: customization can drain battery life ..." Based on these arguments and excerpts, we pose the following hypotheses concerning a smartphone's performance and battery life.

Hypothesis 4 (H4). Reviews involving consumers' performance evaluation receive more helpful votes than those without performance evaluation.

Hypothesis 5 (H5). Reviews mentioning consumers' battery consumption are perceived more helpful than those without it.

\section{Research methodology}

To test our hypotheses, we collected 8,642 of product reviews posted on Best Buy's product pages during years between 2015 and 2017-3036 reviews of iPhone, 3801 of Galaxy, 442 of LG, 750 of MotoZ, and 613 of Pixel. From these product reviews, we derived a dependent variable, independent variables of experience and search attributes, and control variables. Details are shown in Table 2.

For estimating the relationship between experience attributes and review helpfulness, we devised the following hierarchical regression models. Model 1 includes control variables, such as each review's rating [e.g., 7, 17], the types of phones (e.g., ordinary or premium), and each phone's release year. Model 2 adds Model 1 search attributes. Model 3 adds Model 1 experience attributes. The last model, Model 4, consists 
of the control variables, search, and experience attributes (see Figure 2). Helpfulness is a non-negative, count variable that indicates each review's number of helpful votes. Its discrete distribution does fit better with a Poisson distribution than a normal distribution [32]. Specifically, we confirmed from the likelihood-ratio test of alpha that helpfulness in our review data is overdispersed, so a negative binomial model is more appropriate than a Poisson model $[32,33]$.
Another important factor to consider is reviews with zero helpful votes. It turned out that only 741 reviews out of 8642 received at least 1 helpful vote. The other reviews received zero helpful votes. It is likely that the binomial model underestimates excess zeros and possibly produces inconsistent statistical results [34]. The significance of the Vuong test on Model 4 $\left(z=6.52^{* * *}\right)$ indicated that a zero-inflated negative binomial (ZINB) model is more plausible for our review

Table 2. Variable description

\begin{tabular}{|c|c|c|c|c|c|}
\hline Variables & \multicolumn{2}{|c|}{ Explanation } & Mean & Std. Dev. & Range \\
\hline Helpfulness $_{i}$ & \multicolumn{2}{|c|}{ The number of consumer review $i$ 's helpful votes } & 0.465 & 4.2 & $0-140$ \\
\hline Easy-Use_YN & \multicolumn{5}{|c|}{ A contrast code to indicate whether reviews include ease-of-use-1 for 'Yes'; -1 for 'No' } \\
\hline Design_YN & \multicolumn{5}{|c|}{ A contrast code to indicate whether reviews include design-1 for 'Yes'; -1 for 'No' } \\
\hline Performance_YN & \multicolumn{5}{|c|}{ A contrast code to indicate whether reviews include performance-1 for 'Yes'; -1 for 'No' } \\
\hline Sound_YN & \multicolumn{5}{|c|}{ A contrast code to indicate whether reviews include sound-1 for 'Yes'; -1 for 'No' } \\
\hline Battery-Life_YN & \multicolumn{5}{|c|}{ A contrast code to indicate whether reviews include battery - 1 for 'Yes'; -1 for 'No' } \\
\hline Processor_YN & \multicolumn{5}{|c|}{ A contrast code to indicate whether reviews include processor-1 for 'Yes'; -1 for 'No' } \\
\hline Memory_YN & \multicolumn{5}{|c|}{ A contrast code to indicate whether reviews include memory -1 for 'Yes'; -1 for 'No' } \\
\hline Screen_YN & \multicolumn{5}{|c|}{ A contrast code to indicate whether reviews include screen-1 for 'Yes'; -1 for 'No' } \\
\hline Camera_YN & \multicolumn{5}{|c|}{ A contrast code to indicate whether reviews include camera-1 for 'Yes'; -1 for 'No' } \\
\hline Rating $_{i}$ & \multicolumn{2}{|l|}{ Consumer review $i$ 's rating } & 4.75 & 0.56 & $1-5$ \\
\hline \multirow[t]{2}{*}{ OrdinaryVSPremium } & \multicolumn{5}{|c|}{$\begin{array}{l}\text { Two orthogonal contrast codes to compare (1) ordinary phones (MotoZ, LG, and Pixel) with } \\
\text { premium phones (iPhone and Galaxy) and to compare (2) iPhone with Galaxy }\end{array}$} \\
\hline & Contrast codes $\quad$ Products & MotoZ, LG, Pixel & iPhone & Galaxy & \\
\hline \multirow{2}{*}{ iPhoneVSGalaxy } & OrdinaryVSPremium & 2 & -1 & -1 & \\
\hline & iPhoneVSGalaxy & 0 & 1 & -1 & \\
\hline 2015 & \multicolumn{5}{|c|}{ A dummy code to indicate whether a product was releases in 2015} \\
\hline 2016 & \multicolumn{5}{|c|}{ A dummy code to indicate whether a product was releases in 2016} \\
\hline Unhelpful & \multicolumn{2}{|l|}{ Consumer review $i$ 's unhelpful votes } & 0.31 & 8.89 & $0-140$ \\
\hline Days $_{i}$ & \multicolumn{2}{|c|}{$\begin{array}{l}\text { The age of consumer review } i \text {-Difference in days between } \\
\text { review } i \text { 's posting date and review } j \text { 's, where review } j \text { is the } \\
\text { first review of review } i \text { 's product }\end{array}$} & 171.5 & 113.3 & $0-580$ \\
\hline
\end{tabular}

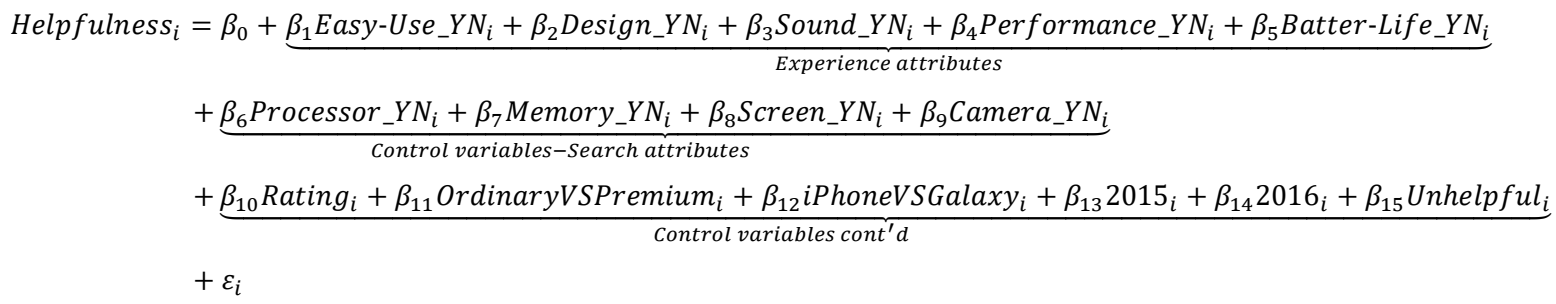

Figure 2. Empirical model of Model 4 
data over the standard Poisson models [35].

As Cameron and Trivedi suggested [32], we estimated our models with robust standard errors. From

Table 3. Results of hierarchical regressions

\begin{tabular}{|c|c|c|c|c|c|}
\hline $\begin{array}{|ll|}\text { Variables } & \text { Models } \\
\end{array}$ & Model 1 & Model 2 & Model 3 & Model 4 & Model 5 \\
\hline \multicolumn{6}{|l|}{ Experience attributes } \\
\hline Easy-Use_YN & - & 一 & $\begin{array}{l}0.0204 \\
(0.0794)\end{array}$ & $\begin{array}{l}0.0207 \\
(0.0797)\end{array}$ & $\begin{array}{l}0.0550 \\
(0.0855)\end{array}$ \\
\hline Design_YN & - & - & $\begin{array}{l}0.392^{* * * *} \\
(0.0770)\end{array}$ & $\begin{array}{l}0.375^{* * *} \\
(0.0717)\end{array}$ & - \\
\hline Sound_YN & - & - & $\begin{array}{l}0.219^{* * *} \\
(0.0797)\end{array}$ & $\begin{array}{l}0.205^{* * *} \\
(0.0761)\end{array}$ & - \\
\hline Perforormace_YN & - & - & $\begin{array}{l}0.459^{* * * *} \\
(0.0937) \\
\end{array}$ & $\begin{array}{l}0.438^{* * *} \\
(0.0911) \\
\end{array}$ & - \\
\hline Battery-Life_YN & - & - & $\begin{array}{l}0.367^{* * * *} \\
(0.0714)\end{array}$ & $\begin{array}{l}0.367^{* * * *} \\
(0.0725)\end{array}$ & - \\
\hline \multicolumn{6}{|l|}{\begin{tabular}{|l|} 
Search attributes \\
\end{tabular}} \\
\hline Processor_YN & - & $\begin{array}{l}0.00583 \\
(0.172)\end{array}$ & - & $\begin{array}{l}-0.135 \\
(0.170)\end{array}$ & - \\
\hline Memory_YN & - & $\begin{array}{l}0.265 \\
(0.143)\end{array}$ & - & $\begin{array}{l}0.0397 \\
(0.105)\end{array}$ & - \\
\hline Screen_YN & - & $\begin{array}{l}0.338^{* * * *} \\
(0.0933)\end{array}$ & - & $\begin{array}{l}0.0842 \\
(0.0700)\end{array}$ & - \\
\hline Camera_YN & - & $\begin{array}{l}0.113 \\
(0.0736)\end{array}$ & - & $\begin{array}{l}0.0526 \\
(0.0645)\end{array}$ & - \\
\hline \multicolumn{6}{|l|}{\begin{tabular}{|l|} 
Control variables \\
\end{tabular}} \\
\hline Rating $_{i}$ & $\begin{array}{l}-0.149 \\
(0.0967)\end{array}$ & $\begin{array}{l}-0.173 \\
(0.0972)\end{array}$ & $\begin{array}{l}-0.103 \\
(0.101)\end{array}$ & $\begin{array}{l}-0.101 \\
(0.101)\end{array}$ & $\begin{array}{l}-0.141 \\
(0.0996)\end{array}$ \\
\hline OrdinaryVSPremium & $\begin{array}{l}0.764^{* * * *} \\
(0.0697)\end{array}$ & $\begin{array}{l}0.661^{* * * *} \\
(0.0669)\end{array}$ & $\begin{array}{l}0.517^{* * * *} \\
(0.0540) \\
\end{array}$ & $\begin{array}{l}0.505^{* * *} \\
(0.0541) \\
\end{array}$ & $\begin{array}{l}0.760^{* * * *} \\
(0.0677)\end{array}$ \\
\hline iPhoneVSGalaxy & $\begin{array}{l}-0.321^{*} \\
(0.163)\end{array}$ & $\begin{array}{l}-0.280 \\
(0.150)\end{array}$ & $\begin{array}{l}-0.304^{*} \\
(0.127) \\
\end{array}$ & $\begin{array}{l}-0.292^{*} \\
(0.124) \\
\end{array}$ & $\begin{array}{l}-0.307 \\
(0.161) \\
\end{array}$ \\
\hline 2015 & $\begin{array}{l}1.771^{* * * *} \\
(0.416)\end{array}$ & $\begin{array}{l}2.040^{* * * *} \\
(0.390)\end{array}$ & $\begin{array}{l}2.145^{* * * *} \\
(0.355)\end{array}$ & $\begin{array}{l}2.196^{* * *} \\
(0.364)\end{array}$ & $\begin{array}{l}1.740^{* * * *} \\
(0.416)\end{array}$ \\
\hline 2016 & $\begin{array}{l}0.691^{* * * *} \\
(0.209)\end{array}$ & $\begin{array}{l}0.835^{* * * *} \\
(0.224)\end{array}$ & $\begin{array}{l}0.663^{* *} \\
(0.204)\end{array}$ & $\begin{array}{l}0.695^{* *} \\
(0.215)\end{array}$ & $\begin{array}{l}(0.410) \\
0.686^{* * * *} \\
(0.208)\end{array}$ \\
\hline Unhelpful $_{i}$ & $\begin{array}{l}0.401^{* * * *} \\
(0.0958)\end{array}$ & $\begin{array}{l}0.387^{* * * *} \\
(0.105)\end{array}$ & $\begin{array}{l}0.370^{* * * *} \\
(0.0988)\end{array}$ & $\begin{array}{l}0.376^{* * *} \\
(0.105)\end{array}$ & $\begin{array}{l}0.397^{* * * *} \\
(0.0961)\end{array}$ \\
\hline Constant & $\begin{array}{l}-1.157^{*} \\
(0.546)\end{array}$ & $\begin{array}{l}-0.906 \\
(0.624)\end{array}$ & $\begin{array}{l}-0.998 \\
(0.588)\end{array}$ & $\begin{array}{l}-1.145 \\
(0.658)\end{array}$ & $\begin{array}{l}-1.158^{*} \\
(0.565)\end{array}$ \\
\hline \multicolumn{6}{|l|}{ Inflate } \\
\hline Days $_{i}$ & $\begin{array}{l}0.0175^{* * * *} \\
(0.00113)\end{array}$ & $\begin{array}{l}0.0176^{* * *} \\
(0.00115)\end{array}$ & $\begin{array}{l}0.0179^{* * *} \\
(0.00123)\end{array}$ & $\begin{array}{l}0.0180^{* * * *} \\
(0.00124)\end{array}$ & $\begin{array}{l}0.0175^{* * * *} \\
(0.00112)\end{array}$ \\
\hline Constant & $\begin{array}{l}-2.834^{* * *} \\
(0.274)\end{array}$ & $\begin{array}{l}-2.959^{* * *} \\
(0.270)\end{array}$ & $\begin{array}{l}-3.219^{* * * *} \\
(0.256)\end{array}$ & $\begin{array}{l}-3.268^{* * *} \\
(0.262)\end{array}$ & $\begin{array}{l}-2.818^{* * * *} \\
(0.272)\end{array}$ \\
\hline \multicolumn{6}{|l|}{\begin{tabular}{|l|} 
Inalpha \\
\end{tabular}} \\
\hline Constant & $\begin{array}{l}1.919^{* * * *} \\
(0.144)\end{array}$ & $\begin{array}{l}1.884^{* * * *} \\
(0.136)\end{array}$ & $\begin{array}{l}1.749^{* * * *} \\
(0.148)\end{array}$ & $\begin{array}{l}1.751^{* * * *} \\
(0.147)\end{array}$ & $\begin{array}{l}1.914^{* * * *} \\
(0.141)\end{array}$ \\
\hline \multicolumn{6}{|l|}{ Model summary } \\
\hline McFadden's $R^{2}$ & 0.158 & 0.164 & 0.187 & 0.187 & 0.158 \\
\hline Likelihood Ratio (LR) & $\mathrm{LR}(8)=1303.0$ & $L R(12)=1356.5$ & $\operatorname{LR}(13)=1541.7$ & $\operatorname{LR}(17)=1545.9$ & $\operatorname{LR}(9)=1302.0$ \\
\hline
\end{tabular}

${ }^{\dagger}$ All predictors are mean centered in the regressions.

${ }^{\dagger}$ Unstandardized regression coefficients with robust errors are shown $\left({ }^{*} \mathrm{p}<0.05,{ }^{* *} \mathrm{p}<0.01,{ }^{* * *} \mathrm{p}<0.001\right)$. 
the variance inflation factor analysis on Model 4, we were informed that multicollinearity is not a concern (Mean=1.21; $\operatorname{Max}=1.77)$.

\section{Results}

The regression results are shown in Table 3 . We evaluated the hypotheses by utilizing Model 4, which is the most comprehensive empirical model.

$\mathrm{H} 1$ is not supported, as no significant evidence is found supporting that consumers' ease-of-use experience is helpful experiential information $\left(\beta_{\text {Easy- }}\right.$ Use_YN=0.0207, $p=0.796$ ).

Consumers' personal values on design were perceived helpful, in the sense that reviews including such personal values are expected to have a rate 2.117 times greater for helpful votes than those without such information $\left(\beta_{\text {Design_YN }}=0.375^{* * *}\right)$, supporting $\mathrm{H} 2$.

H3 is supported. There exists a significant difference between product reviews conveying consumers' sound experience and those without such experience $\left(\beta_{\text {Sound_YN }_{1}}=0.205^{* *}\right)$ - the former is expected to have a rate 1.507 times greater for helpful votes than the latter.

H4 stating consumers' performance experience turns out significant $\left(\beta_{\text {Performance_YN }}=0.438^{* * * *}\right)$ - a rate for helpful votes is higher by 2.4 times for reviews with consumers' performance experience than for those with it.

\subsection{Predictive analysis}

We further corroborate the main findings of this study by performing predictive analytics on the same review data. That is, by utilizing two popular classification algorithms of neural networks and random forests, we examined the capability of experience attributes' information to predict whether unobserved reviews will be evaluated "helpful" by helpfulness ratio, a ratio between a review's helpful votes and its total votes (i.e., helpful and unhelpful votes). When a review's helpfulness ratio is greater than or equal to 0.5 , it is considered "helpful" or "unhelpful" otherwise.

Using the helpfulness ratio as a target variable, we formed the following two predictive models: (1) Predictive Model 1 (PM 1) with search attributesProcessor_YN, Memory_YN, Screen_YN, and Camera_YN; (2) Predictive Model 2 (PM 2) with experience attributes-Easy-Use_YN, Design_YN, Sound_YN, Performance_YN, and Batter-life_YN. To train PMs 1 and 2's classifiers and evaluate their predictive capabilities, we followed Steps 1 to 4: Step 1 -we randomly selected 500 helpful reviews and another set of 500 unhelpful reviews to minimize the possible biases of classifiers [36]; Step 2-the selected 1000 reviews were split into a training set $(70 \%)$ to build classifiers and test set (30\%) to evaluate each classifier's prediction accuracy; Step 3-we repeated Steps 1 and 2

Table 4. Classifiers' prediction accuracy by AUC

\begin{tabular}{|c|c|c|c|c|c|c|}
\hline \multirow{2}{*}{\begin{tabular}{|l|l|l|l}
$\begin{array}{l}\text { 10-fold cross } \\
\text { validation }\end{array}$ & $\begin{array}{l}\text { Predictive } \\
\text { models }\end{array}$ \\
\end{tabular}} & \multicolumn{3}{|c|}{ Neural networks } & \multicolumn{3}{|c|}{ Random forests } \\
\hline & PM 1 & PM 2 & Difference $^{4}$ & PM 1 & PM 2 & Difference \\
\hline 1 & 0.635 & 0.782 & 0.147 & 0.634 & 0.704 & 0.070 \\
\hline 2 & 0.589 & 0.704 & 0.115 & 0.595 & 0.692 & 0.097 \\
\hline 3 & 0.561 & 0.633 & 0.072 & 0.553 & 0.641 & 0.088 \\
\hline 4 & 0.623 & 0.729 & 0.106 & 0.606 & 0.702 & 0.096 \\
\hline 5 & 0.609 & 0.704 & 0.095 & 0.578 & 0.66 & 0.082 \\
\hline 6 & 0.618 & 0.705 & 0.087 & 0.613 & 0.723 & 0.110 \\
\hline 7 & 0.576 & 0.702 & 0.126 & 0.557 & 0.704 & 0.147 \\
\hline 8 & 0.607 & 0.687 & 0.080 & 0.611 & 0.697 & 0.086 \\
\hline 9 & 0.644 & 0.735 & 0.091 & 0.636 & 0.691 & 0.055 \\
\hline 10 & 0.607 & 0.684 & 0.077 & 0.608 & 0.676 & 0.068 \\
\hline Mean & 0.607 & 0.707 & 0.100 & 0.599 & 0.689 & 0.090 \\
\hline
\end{tabular}

Last, we found significant evidence supporting H5. Reviews including consumers' battery consumption are expected to receive helpful votes by 2.083 times higher than those without such consumption information $\left(\beta_{\text {Battery-Life_YN }}=0.367^{* * *}\right)$.

\footnotetext{
${ }^{4}$ Difference in prediction accuracy between PM1 and PM2
}

for 10 times, called $n$-fold cross validation, in order to assess the generalizability of the classifiers [37]. The prediction accuracy of classifiers was assessed by the Area Under a ROC Curve (AUC). The AUC values range from 0.0 (i.e., zero prediction accuracy), 0.5 (i.e., random guessing), to 1.0 (i.e., perfect prediction 
accuracy) [38]. Table 4 shows the AUC values of PMs 1 and 2's classifiers.

PM 1's neural network classifiers improved the prediction accuracy by $10.9 \%(0.609)$ on average from random guessing and its random forests classifier's by 10\% (0.6), while PM 2's neural network and random forests classifiers showed an accuracy improvement by $20.7 \%(0.707)$ and $18.6 \%(0.686)$, respectively. The ROC curves shown in Figure 3 visualize PMs 1 and 2's classification performance by the true positives (or sensitivity) and the false positives (or 1-specificity) at $10^{\text {th }}$ iteration. $^{5}$ On average, PM 2's accuracy is significantly higher by $9.25 \%$ than that of PM 1, while controlling for the types of algorithms $\left(\beta=0.0463^{* * *}, F_{1}\right.$, $\left.{ }_{38}=115.49, R^{2}=0.7424\right)$. Therefore, we conclude that the experiential-centric product information (e.g., experience attributes) is a stronger factor affecting review helpfulness than the fact-centric product information (e.g., search attributes). personal values on the smartphone's design, sound, performance, and battery life were perceived helpful. On the other hand, four search attributes of processor, memory, screen, and camera were insignificant in explaining review helpfulness (see Model 4 of Table 3).

The empirical results well support the notion of information seeking, decision making, and uncertainty reduction [2, 9], in the sense that while consumers' experience-centric information adds distinct value to reduce uncertainty about product quality over and above MGC's, consumers' fact-centric information does not add extra value to what MGC conveys. By the predictive analytics, we are further convinced of the value of consumers' experiential information-the classifiers using the experience attributes (PM 2) improved the prediction accuracy of product reviews to be helpful or unhelpful by $9.25 \%$ on average, compared to that of the classifiers with the search attributes (PM 1).

This study opens opportunities for future research.

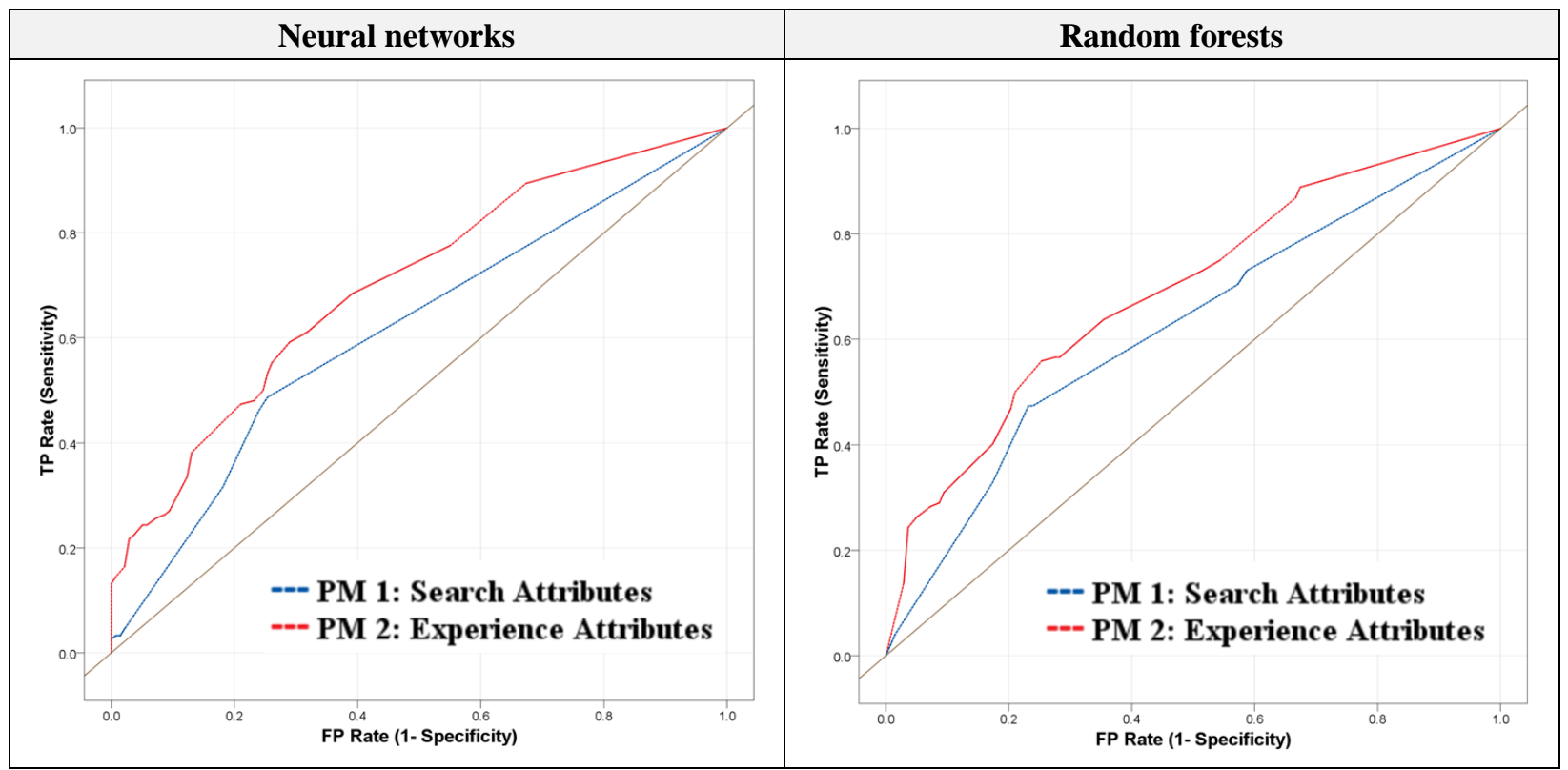

Figure 3. ROC Curves by neural network (left) and random forests (right)

\section{Discussion}

This study examined consumers-generated product information by distinguishing consumer's experiencecentric information (or experience attributes) from factcentric information (or search attributes). We found the following five experience attributes in the smartphone reviews-Ease of Use, Design, Sound, Performance, and Battery-Life. Then, we performed the hypothesis testing for these experience attributes in association with review helpfulness. It turned out that most of consumers'

${ }^{5}$ Sensitivity - a classifier's ability to correctly predict a review to be helpful, when it is helpful (helpfulness ratio >=0.5); Specificity-a
First, consumers' ease-of-use experience was not significantly related to review helpfulness, a discrepancy between this study and others on technology products [e.g., 25, 39]. One possible explanation would be that most of prospective customers are experienced users of smartphones and thus they had their own ease-of-use experience. According to a report by Pew Research Center, 96\% of Americans owned handheld devices, such as mobile

classifier's ability to correctly foretell a review to be unhelpful, when it is unhelpful (helpfulness ratio $<0.5$ ). 
phones in 2019. ${ }^{6}$ Consequently, such experience of other consumers may not be deemed valuable. Another possible surmise is that the effect of ease-of-use may be redundant with the other experience and search attributes. We investigated this conjecture by establishing an empirical model that includes an easeof-use attribute and the control variables (see Model 5 of Table 3). We found from Model 5 that regardless of the other attributes, the effect of ease-of-use was insignificant for review helpfulness $\left(\beta_{\text {Easy-Use_YN }}=0.055\right.$, $p=0.52$ ). Future research may contribute to unravel this discrepancy by considering the extent of prospective customers' year of smartphone experience or by identifying the intention of switching platforms (e.g., from iOS-based phones to Android-based phones or vice versa). Second, instead of using a binary indicator of whether a review includes an experience attribute or not, we may devise a better measurement unit to reflect experience and search attributes (e.g., a review conveys $30 \%$ of battery life, $40 \%$ of performance, and $30 \%$ of ease-of-use.).

\section{Conclusion}

According to a report issued in 2019 by Qualtrics, more than $90 \%$ of online shoppers aged between 18 and 34 have confidence in online reviews as personal recommendation, and $68 \%$ of consumers are willing to

\section{References}

[1] P. A. Pavlou, H. Liang, and Y. Xue, "Understanding and mitigating uncertainty in online exchange relationships: A principal-agent perspective," MIS Quarterly, vol. 31, no. 1, pp. 105-136, 2007.

[2] J. D. Wells, J. S. Valacich, and T. J. Hess, "What signal are you sending? How website quality influences perceptions of product quality and purchase intentions," MIS Quarterly, vol. 35, no. 2, pp. 373-396, 2011.

[3] A. Kirmani and A. R. Rao, "No pain, no gain: A critical review of the literature on signaling unobservable product quality," Journal of Marketing, vol. 64, no. 2, pp. 66-79, 2000.

[4] K.-Y. Goh, C.-S. Heng, and Z. Lin, "Social media brand community and consumer behavior: Quantifying the relative impact of user-and marketer-generated content," Information Systems Research, vol. 24, no. 1, pp. 88-107, 2013.

[5] A. Dimoka, Y. Hong, and P. A. Pavlou, "On product uncertainty in online markets: Theory and evidence," MIS Quarterly, vol. 36, pp. 395-426, 2012.

[6] J. Son, A. Negahban, Y. Lee, J. Connolly, and D. Chiang, "When More is More and Less is More: Depth and Breadth of Product Reviews and Their Effects on post a product review if asked [40]. Certainly, consumer-oriented product information impacts the purchase decision of prospective customers. However, not all information in product reviews is helpful. Rather, consumers' experiential information actually makes their reviews informative.

This study contributes to the extant literature of ecommerce and online information seeking. By focusing on the qualitative aspect (i.e., content) of product reviews, we demonstrated the importance of consumers' product experience stemmed from their real usage patterns. That is, this study sheds light on consumers' experience-centric information, which is not intensively tackled yet, but conveys meaningful implication to understand the nature of consumer-oriented product information. The findings of this study suggest the following practical contributions. For e-commerce sites, organizing and presenting product reviews by centering on consumers' diverse experience can facilitate online customers to obtain more informative product reviews in a timely manner. For consumers, sharing personal values with others will make product reviews more persuasive than listing up objective product features. Altogether, our research efforts shed light on the importance of exploring review content in order to better understand consumer-oriented product information.

Review Helpfulness," in 53rd Hawaii International Conference on System Sciences, Maui, HI, 2020.

[7] S. M. Mudambi and D. Schuff, "What makes a helpful online review? A study of customer reviews on Amazon. com," MIS Quarterly, vol. 34, no. 1, pp. 185200, 2010.

[8] N. Hu, N. S. Koh, and S. K. Reddy, "Ratings lead you to the product, reviews help you clinch it? The mediating role of online review sentiments on product sales," Decision Support Systems, vol. 57, pp. 42-53, 2014.

[9] D. O. Case and L. M. Given, Looking for information: A survey of research on information seeking, needs, and behavior. Emerald Group Publishing, 2016.

[10] P. A. Pavlou and A. Dimoka, "The nature and role of feedback text comments in online marketplaces: Implications for trust building, price premiums, and seller differentiation," Information Systems Research, vol. 17, no. 4, pp. 392-414, 2006.

[11] C. Dellarocas, "The digitization of word of mouth: Promise and challenges of online feedback mechanisms," Management Science, vol. 49, no. 10, pp. 1407-1424, 2003.

[12] C.-H. Yeh, Y.-S. Wang, and K. Yieh, "Predicting smartphone brand loyalty: Consumer value and consumer-brand identification perspectives," International Journal of Information Management, vol. 36, no. 3, pp. 245-257, 2016.

\footnotetext{
${ }^{6} \mathrm{https}: / /$ www.pewresearch.org/internet/fact-sheet/mobile/
} 
[13] B. Gu, J. Park, and P. Konana, "Research note-the impact of external word-of-mouth sources on retailer sales of high-involvement products," Information Systems Research, vol. 23, no. 1, pp. 182-196, 2012.

[14] X. Li, L. M. Hitt, and Z. J. Zhang, "Product reviews and competition in markets for repeat purchase products," Journal of Management Information Systems, vol. 27, no. 4, pp. 9-42, 2011.

[15] G. Lackermair, D. Kailer, and K. Kanmaz, "Importance of online product reviews from a consumer's perspective," Advances in Economics and Business, vol. 1, no. 1, pp. 1-5, 2013.

[16] Y. Wan and M. Nakayama, "The reliability of online review helpfulness," Journal of Electronic Commerce Research, vol. 15, no. 3, p. 179, 2014.

[17] H. Hong, D. Xu, G. A. Wang, and W. Fan, "Understanding the determinants of online review helpfulness: A meta-analytic investigation," Decision Support Systems, vol. 102, pp. 1-11, 2017.

[18] Z. Liu and S. Park, "What makes a useful online review? Implication for travel product websites," Tourism Management, vol. 47, pp. 140-151, 2015.

[19] K. K. Kuan, K.-L. Hui, P. Prasarnphanich, and H.-Y. Lai, "What makes a review voted? An empirical investigation of review voting in online review systems," Journal of the Association for Information Systems, vol. 16, no. 1, p. 1, 2015.

[20] H. Baek, J. Ahn, and Y. Choi, "Helpfulness of online consumer reviews: Readers' objectives and review cues," International Journal of Electronic Commerce, vol. 17, no. 2, pp. 99-126, 2012.

[21] Q. Cao, W. Duan, and Q. Gan, "Exploring determinants of voting for the "helpfulness" of online user reviews: A text mining approach," Decision Support Systems, vol. 50, no. 2, pp. 511-521, 2011.

[22] V. A. Zeithaml, "Consumer perceptions of price, quality, and value: a means-end model and synthesis of evidence," Journal of Marketing, vol. 52, no. 3, pp. 222, 1988.

[23] M. B. Holbrook, "Integrating compositional and decompositional analyses to represent the intervening role of perceptions in evaluative judgments," Journal of Marketing Research, vol. 18, no. 1, pp. 13-28, 1981.

[24] D. M. Gardner, F. Johnson, M. Lee, and I. Wilkinson, "A contingency approach to marketing high technology products," European Journal of Marketing, vol. 34, no. 9,2000

[25] S. Lee, S. Ha, and R. Widdows, "Consumer responses to high-technology products: Product attributes, cognition, and emotions," Journal of Business Research, vol. 64, no. 11, pp. 1195-1200, 2011.

[26] C. Liao and I. Hsieh, "Determinants of consumer's willingness to purchase gray-market smartphones," Journal of Business Ethics, vol. 114, no. 3, pp. 409-424, 2013.

[27] Y. Chen and J. Xie, "Online consumer review: Wordof-mouth as a new element of marketing communication mix," Management Science, vol. 54, no. 3, pp. 477-491, 2008.
[28] F. D. Davis, "Perceived usefulness, perceived ease of use, and user acceptance of information technology," MIS Quarterly, vol. 13, no. 3, pp. 319-340, 1989.

[29] P. H. Bloch, "Seeking the ideal form: Product design and consumer response," Journal of Marketing, vol. 59, no. 3, pp. 16-29, 1995.

[30] J. Otterbacher, "Searching for product experience attributes in online information sources," in International Conference on Information Systems, Paris, France, 2008, p. 207.

[31] D. Ferreira, A. K. Dey, and V. Kostakos, "Understanding human-smartphone concerns: a study of battery life," in International Conference on Pervasive Computing, Seattle, USA, 2011: Springer, pp. 19-33.

[32] A. C. Cameron and P. K. Trivedi, Regression analysis of count data. Cambridge University Press, 2013.

[33] J. M. Hilbe, Negative binomial regression. Cambridge University Press, 2011.

[34] C. Gourieroux, A. Monfort, and A. Trognon, "Pseudo maximum likelihood methods: Theory," Econometrica: Journal of the Econometric Society, vol. 52, no. 3, pp. 681-700, 1984.

[35] Q. H. Vuong, "Likelihood ratio tests for model selection and non-nested hypotheses," Econometrica: Journal of the Econometric Society, vol. 57, no. 2, pp. 307-333, 1989.

[36] S. B. Kotsiantis, I. Zaharakis, and P. Pintelas, "Supervised machine learning: A review of classification techniques," Emerging Artificial Intelligence Applications in Computer Engineering, vol. 160, pp. 3-24, 2007.

[37] T. Wendler and S. Gröttrup, Data mining with SPSS modeler: theory, exercises and solutions. Springer, 2016.

[38] T. Fawcett, "An introduction to ROC analysis," Pattern Recognition Letters, vol. 27, no. 8, pp. 861-874, 2006.

[39] V. P. Rindova and A. P. Petkova, "When is a new thing a good thing? Technological change, product form design, and perceptions of value for product innovations," Organization Science, vol. 18, no. 2, pp. 217-232, 2007.

[40] D. Kaemingk. "20 online review stats to know in 2019." Qualtrics. https://www.qualtrics.com/blog/onlinereview-stats/ (accessed Feb. 29, 2020). 